\title{
Microwave-assisted catalytic esterification of a-glucoisosaccharino-1,4-lactone with tall oil fatty acids
}

Hemanathan Kumar* and Raimo Alén ${ }^{*}$

\begin{abstract}
Background: Carbohydrates-rich materials are partly degraded during alkaline kraft pulping into a complex mixture of aliphatic carboxylic acids consisting of a-glucoisosaccharinic acid as one of the main acids. On the other hand, crude tall oil, containing significant amounts fatty acids, is obtained as a by-product from kraft pulping. One interesting novel approach is to utilize chemically both these side-streams by producing renewable surfactants from aliphatic carboxylic acids and fatty acids via esterification.

Results: In this paper, lauric $\left(C_{12: 0}\right)$ and oleic $\left(C_{18: 1}\right)$ acids as well as a mixture of tall oil fatty acids were esterified with a-glucoisosaccharino-1,4-lactone in a microwave-assisted batch reactor using a respective molar ratio of 3:1 in the presence of $p$-toluenesulfonic acid as a catalyst to obtain a mixture of the corresponding mono- and diesters (nonionic surfactants) at $70-100{ }^{\circ} \mathrm{C}$ for $6-24 \mathrm{~h}$. The total yields varied in the range of $40-62 \%$ and the mass ratio of monoesters to diesters (0.4-2.7) was greatly dependent on the fatty acid feedstock.

Conclusions: It seems that relatively high yields of mono- and diesters of typical fatty acids can be obtained when they are esterified with one of the most significant lactones (a-glucoisosaccharino-1,4-lactone) in black liquor from kraft pulping. These esters are potential surfactants based on renewable feedstocks.
\end{abstract}

Keywords: Glucoisosaccharinic acid, Lauric acid, Oleic acid, Tall oil fatty acids, Esterification, Batch reactor, Kraft pulping, Microwave

\section{Background}

During kraft pulping, about half of the initial wood material is dissolved in the cooking liquor ("black liquor", BL) [1]. BL typically contains degraded lignin, aliphatic carboxylic acids, and inorganic compounds, as well as small amounts of extractives and hemicellulose residues. In the kraft pulping industry, the tall oil soap, mainly containing sodium salts of fatty and resin acids, is removed by skimming from the BL during its multiple-effect evaporation before burning in a recovery furnace to generate energy and recover the inorganic cooking chemicals [2].

Conventionally, crude tall oil (CTO) is obtained from the tall oil soap by adding sulfuric acid to liberate free fatty and resin acids [1]. The CTO is then further purified

*Correspondence: hemanathan.k.kumar@jyu.fi; raimo.j.alen@jyu.fi Laboratory of Applied Chemistry, University of Jyvaskyla, P.O. Box 35, 40014 Jyväskylä, Finland and fractionated by vacuum distillation to obtain several commercial fractions including tall oil fatty acids (TOFAs) (20-40 \%), tall oil rosin (TOR) (25-35\%), light oil (10-15\%), and pitch residue (20-30\%) [2-4]. The average yield of CTO is in the range of $30-50 \mathrm{~kg} / \mathrm{ton}$ of pulp. In general, oleic $\left(\mathrm{C}_{18: 1}\right)$ and linoleic $\left(\mathrm{C}_{18: 2}\right)$ acids are the most significant fatty acid components in TOFAs. Recently, TOFAs are used as such or as various derivatives in many commercial applications including, for example, the manufacture of paints, surfactants, inks, and fuel additives [5-8].

The main fraction of aliphatic carboxylic acids in BL contains volatile acids (formic and acetic acids) together with non-volatile hydroxy carboxylic acids $[1,9]$. The hydroxy acids, originating from feedstock carbohydrates by alkali-catalyzed degradation reactions, can be further divided into low-molar-mass (LMM) hydroxy acids with $2-4$ carbon atoms (mainly glycolic, lactic, and 
2-hydroxybutanoic acids) and high-molar-mass (HMM) hydroxy acids with 5 or 6 carbon atoms (mainly 3,4-dideoxy-pentonic, 3-deoxy-pentonic, xyloisosaccharinic, and $\alpha$ - and $\beta$-glucoisosaccharinic ( $\alpha$ - and $\beta$-GISA, respectively) acids $[1,10]$.

Since the aliphatic carboxylic acids are formed in considerable amounts in the pulping industry, their partial recovery has gradually become an interesting alternative to using them as fuel [11]. On the other hand, carboxylic acids possess a low heating value in comparison to that of lignin. Therefore, their recovery from BL reduces the heat content of BL less than expected [11-13]. It has also been studied potential process alternatives for separating sodium-free aliphatic acids $[1,14,15]$. Aliphatic carboxylic acids are used in numerous applications as single components or as more or less purified mixtures. Especially, the LMM acids are commercially utilized for many purposes. However, the chemical utilization of the HMM acids is still challenging and it has been studied only to some extent.

The esters of carboxylic acids with carbohydrates ("sugar fatty acid esters") and their ethoxylated derivatives belong to a family of synthetic nonionic surface active agents ("surfactants") [16]. Almost one-fourth of the total industrial production of surfactants account from nonionic surfactants, which are widely used in washing up liquids and personnel care products [17] and as emulsifiers in food, cosmetics, and medicinal products [18-20]. The free HMM hydroxy acids exist as intramolecular cyclic esters (i.e., lactones) [1]. These molecules can also be directly esterified with long chain fatty acids in the presence of an acid catalyst to obtain nonionic surfactants. In addition, the HMM acid lactones contain multiple hydroxyl groups that practically makes possible, besides the formation of monoesters, the preparation of diesters.

In our previous study [10], the separation of the LMM hydroxy acids as their methyl esters as well as the crude fraction of the HMM acid lactones from the hardwood BL was carried out. One interesting approach is to utilize chemically both the HMM acid lactones- and fatty acidscontaining side-streams by producing surfactants via their mutual esterification. The main aim of this basic study was to catalytically esterify $\alpha$-glucoisosaccharino1,4-lactone ( $\alpha$-GISAL) first with lauric $\left(\mathrm{C}_{12: 0}\right)$ and oleic $\left(\mathrm{C}_{18: 1}\right)$ acids and then with a commercial mixture of TOFAs in a microwave-assisted reactor to clarify in more detail the primary reactions taking place (Fig. 1). The esterification of the crude fraction of the HMM acid lactones from BL with a mixture of TOFAs will be studied in the forthcoming investigations.

\section{Experimental}

\section{Chemicals and esterification tests}

$\alpha$-GISAL (3-deoxy-2-C-hydroxymethyl-D-erythro-pentono-1,4-lactone) was prepared from lactose [21] and was gas chromatographically pure (m.p. $94-95{ }^{\circ} \mathrm{C}$ ) [22]. Lauric acid ( $98 \%$, Fluka Chemical Corporation, Seeltze, Germany), oleic acid ( $\geq 99 \%$, Sigma Aldrich, Inc., St. Louis, MO, USA), $p$-toluenesulfonic acid ( $p$ TSA) monohydrate ( $98 \%$, Sigma Aldrich), and the fraction of TOFAs (Forchem Oy, Finland) were commercial products and used without further purification. All the other chemicals and solvents were of analytical grade.

Fatty acid esters of $\alpha$-GISAL were directly prepared using a microwave-assisted batch reactor $(10 \mathrm{~mL})$. The lauric acid $(75.5 \mathrm{mg}, 0.37 \mathrm{mmol}$ ) was added to the $p$ TSA catalyst $(4.5 \mathrm{mg}, 0.026 \mathrm{mmol})$ and $\alpha$-GISAL $(20 \mathrm{mg}$, $0.12 \mathrm{mmol}$ ) was then added in four portions $(5 \mathrm{mg})$ at an interval of $20 \mathrm{~min}$. The resulting suspension was esterified at $100{ }^{\circ} \mathrm{C}$ under magnetic stirring for $6 \mathrm{~h}$. The other esterifications were made in the same way; a fatty acid component of oleic acid (103.4 mg, $0.36 \mathrm{mmol}$ ) and TOFAs $(110 \mathrm{mg}, \sim 0.38 \mathrm{mmol})$ were separately esterified in the presence of $p$ TSA with $\alpha$-GISAL, at $70{ }^{\circ} \mathrm{C}$ for $24 \mathrm{~h}$. In each case, the crude reaction product was collected for further analyses. Two replicates were made for each condition. The ester products could be recovered by dissolution of the reaction mixture into toluene (unreacted $\alpha$-GISAL was removed by decanting) followed by

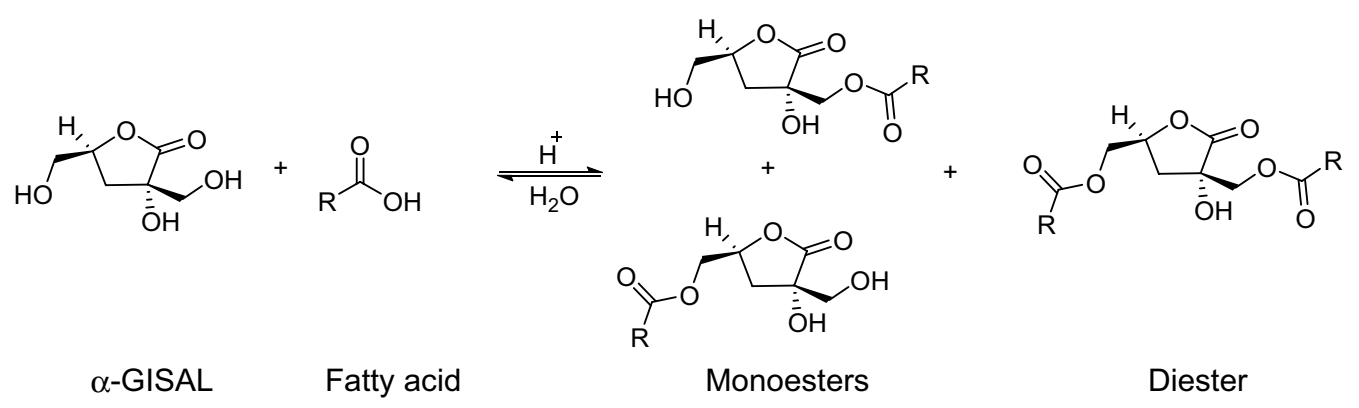

Fig. 1 Principal products of the catalytical esterification of a-GISAL with a fatty acid 
washing the liquid phase in aqueous $\mathrm{KHCO}_{3}$ solution $\left(1 \%\right.$ in $\left.\mathrm{H}_{2} \mathrm{O}\right)$ to precipitate the unreacted fatty acids as an emulsion. Finally, the ester products were obtained by evaporation of the toluene phase to dryness.

\section{Analytical determinations}

The quantitative analysis of TOFAs was performed by GC/FID according to Lappi and Alén [3]. The relative mass-based response factors used between the GC peak areas derived from internal standards (ISs), heneicosanoic acid and betulinol, and those of compounds were equal to 1. $\alpha$-GISAL and the product esters were also determined by GC/FID; in each case, the dried sample was dissolved in toluene $(1: 100 \mathrm{v} / \mathrm{v})$ and then per(trimethylsilyl)ated with a mixture of $0.5 \mathrm{~mL}, O$ bis(trimethylsilyl)trifluoroacetamide (BSTFA) containing $1 \%$ of trimethylchlorosilane (TMCS) in $1 \mathrm{~mL}$ pyridine prior to chromatographic analysis. Xylitol was used as an IS. The identification of the peaks was conducted by a gas chromatograph equipped with a mass selective detector (GC/MSD). The results were analyzed with the Enhanced ChemStation G1701CA (version C.00.00, Agilent Technologies, Palo Alto, CA, USA) software and the mass spectra were compared to those in the Wiley7n database. The relative massbased response factors in relation to that of the IS (1.0) were determined by the separately-purified mono- and dilaurate of $\alpha$-GISA using GC/FID under the same conditions as those in GC/MSD; they were 3.5 and 3.7, respectively. These values were also used for the quantitative determination of other fatty acid mono- and diesters.

HRMS data were obtained in the positive mode using a MicroMass LCT-TOF Premier Spectrometer, Micromass UK Ltd. The results were analyzed using the Mass Lynx software. The accurate sample masses were measured in relation to IS [for monolaurate aspartame, for dilaurate and dioleate erythromycin, and for monooleate 2-(4-hydroxyphenylazo)benzoic acid]. The ${ }^{1} \mathrm{H}$ NMR spectra were recorded in $\mathrm{CDCl}_{3}$ on a Bruker Avance 500 or 300 spectrometer (Bruker Corporation, Billerica, MA, USA). The chemical shifts were reported in ppm relative to the residual $\mathrm{CHCl}_{3}(\delta 7.26)$.

IR spectra were recorded with a Tensor27 FT-IR spectrometer (Bruker $\mathrm{GmbH}$, Germany). The spectra were taken as an average of 32 scans in the wave number between 400 and $4000 \mathrm{~cm}^{-1}$ with a resolution of $4 \mathrm{~cm}^{-1}$.

The formation of esters was also followed by thin-layer chromatography (TLC). The mobile phase consisted of hexane and ethyl acetate in the ratio of 50:50 (v/v). The $R_{f}$ values of lauric acid esters were: 0.74 for a diester and 0.19 and 0.35 for monoesters when esterification took place at the group $\mathrm{C}_{2}$ and $\mathrm{C}_{4}$, respectively.

\section{Results and discussion}

The fraction of TOFAs contained $92.4 \%$ of fatty and $3.2 \%$ of resin acids (Table 1). These composition data were slightly different from those (97.0 and $1.7 \%$, respectively) reported by the manufacturer. This was probably partly due to the "inaccuracies in compound quantification" (i.e., no specific relative response factors between the GC peak areas derived from the internal standards and the individual compounds were used) and the amount of "unidentified compounds" (about $4 \%$ ). The main fatty acid components analyzed were linoleic $\left(\mathrm{C}_{18: 2}\right)$, oleic $\left(\mathrm{C}_{18: 1}\right)$, and linolenic $\left(\mathrm{C}_{18: 3}\right)$ acids which, respectively, comprised of about 50,25 , and $9 \%$ of the total fatty acids.

In the catalytic esterification of $\alpha$-GISAL with lauric acid (i.e., saturated fatty acid) and oleic acid (i.e., unsaturated fatty acid) the rate of esterification reaction under the applied conditions was higher in the former case; the total yield of about $62 \%$ (based on GC data) was obtained for lauric acid esters (Table 2). The corresponding yields of oleic acid esters and TOFA esters were respectively, about 21 and $12 \%$ for the first 6 hours and the maximum

Table 1 Chemical composition of the faction of TOFAs (\% of the total compounds)

\begin{tabular}{lcc}
\hline Compound & & Content \\
\hline Fatty acids & $C_{18: 0}$ & 92.4 \\
Stearic acid & $C_{18: 1}$ & 3.5 \\
Oleic acid & $C_{18: 2}$ & 25.0 \\
Linoleic acid & & 45.4 \\
$C_{18: 2}$ (conjugated) & & 1.0 \\
$C_{18: 2}$ (conjugated) & & 1.6 \\
$C_{18: 2}$ (conjugated) & $C_{18: 3}$ & 2.2 \\
Linolenic acid & & 8.5 \\
C18:3 $_{1 \text { (conjugated) }}$ & 1.0 \\
10-Nonadecenoic acid & $C_{19: 1}$ & 1.2 \\
Eicosatrienoic acid & $C_{20: 3}$ & 1.0 \\
Others & & 2.0 \\
Resin acids & & 3.2 \\
Pimaric acid & & 1.1 \\
8,15-Isopimaridien-18-oic acid & & 2.1 \\
Miscellaneous & & 4.4 \\
\hline
\end{tabular}

${ }^{a}$ Fatty acids which are present in lower concentrations

Table 2 Yields (\%) of the esterification of a-GISAL with fatty acids

\begin{tabular}{lccll}
\hline Fatty acids & Time, $\mathbf{h}$ & Temperature, ${ }^{\circ} \mathbf{C}$ & \multicolumn{2}{l}{ Esters } \\
\cline { 4 - 5 } & & & Mono- & Di- \\
\hline Lauric & 6 & 100 & 16.9 & 45.2 \\
Oleic & 24 & 70 & 43.9 & 16.5 \\
Tall oil & 24 & 70 & 22.9 & 17.6 \\
\hline
\end{tabular}


yields of 60 and $40 \%$ were obtained at a prolonged reaction time. It should be pointed out that at a temperature of above $70{ }^{\circ} \mathrm{C}$ the unsaturated fatty acids were selfpolymerized resulting in a lower ester conversion. The separate test series indicated that with respect to the highest ester yields, the temperatures 70 and $100{ }^{\circ} \mathrm{C}$ were optimum in a microwave assisted reactor for saturated and unsaturated fatty acids, respectively. In addition, it was found that the catalyst $p$ TSA was specific at these temperatures and the formation of undesirable products was avoided.

The high resolution mass spectrometric (HRMS) (ESI+) data are shown in Additional file 1: Figure S1: m/z calculated for $\left[\mathrm{C}_{18} \mathrm{H}_{32} \mathrm{O}_{6} \mathrm{Na}\right]^{+} 367.2091$ (found 367.2094), which corresponded to monolaurate and $\mathrm{m} / \mathrm{z}$ calculated for $\left[\mathrm{C}_{30} \mathrm{H}_{54} \mathrm{O}_{7} \mathrm{Na}\right]^{+} 549.3762$ (found 549.3778 ) representing dilaurate. Similarly, the $\mathrm{m} / \mathrm{z}$ data on mono- and dioleate were, respectively: 449.2874 (calculated for $\left[\mathrm{C}_{24} \mathrm{H}_{42} \mathrm{O}_{6} \mathrm{Na}\right]^{+}$) and 449.2853 (found) and 713.5327 (calculated for $\left[\mathrm{C}_{42} \mathrm{H}_{74} \mathrm{O}_{7} \mathrm{Na}\right]^{+}$) and 713.5313 (found).

The IR spectra of the $\alpha$-GISAL and the lauric esters of $\alpha$-GISAL are shown in Additional file 1: Figure S2. The strong bands were observed in the bands of 3321, 1776, and $1026 \mathrm{~cm}^{-1}$ for $\alpha$-GISAL and in the bands of 3460 ,
1773, 1742, 1710, and $1182 \mathrm{~cm}^{-1}$ for lauric esters of $\alpha$-GISAL.

$\alpha$-GISAL was reacted with a molar ratio of 1:1 and 1:2 to obtain the corresponding mono- and diesterification products. The esterification had a significant impact on the chemical shifts of $\mathrm{H}_{4}$ proton due to the deshielding effect caused by the ester functional groups; thus it was used as a characteristic peak to identify the corresponding monoesterification products. Without any difficulty, a multiplet observed at $4.88 \mathrm{ppm}$ for $\mathrm{H}_{4}$ proton suggested a diester product (Fig. 2a). Esterification of a hydroxymethyl group attached either to $\mathrm{C}_{4}$ or $\mathrm{C}_{2}$ caused the respective downfield and upfield chemical shifts as shown in Fig. 2b, c. The electron withdrawing nature of ester functional group at $\mathrm{C}_{4}$ could be accounted for the downfield chemical shift observed in Fig. 2b. On the other hand, the esterification at $\mathrm{C}_{2}$ group had the long range deactivation effect on $\mathrm{H}_{4}$ proton, thus resulting in the upfield chemical shift as shown in Fig. 2c.

\section{Conclusions}

In kraft pulping, significant amounts of carbohydratesderived hydroxy acids and extractives-derived fatty acids are formed as by-products and they can be partly

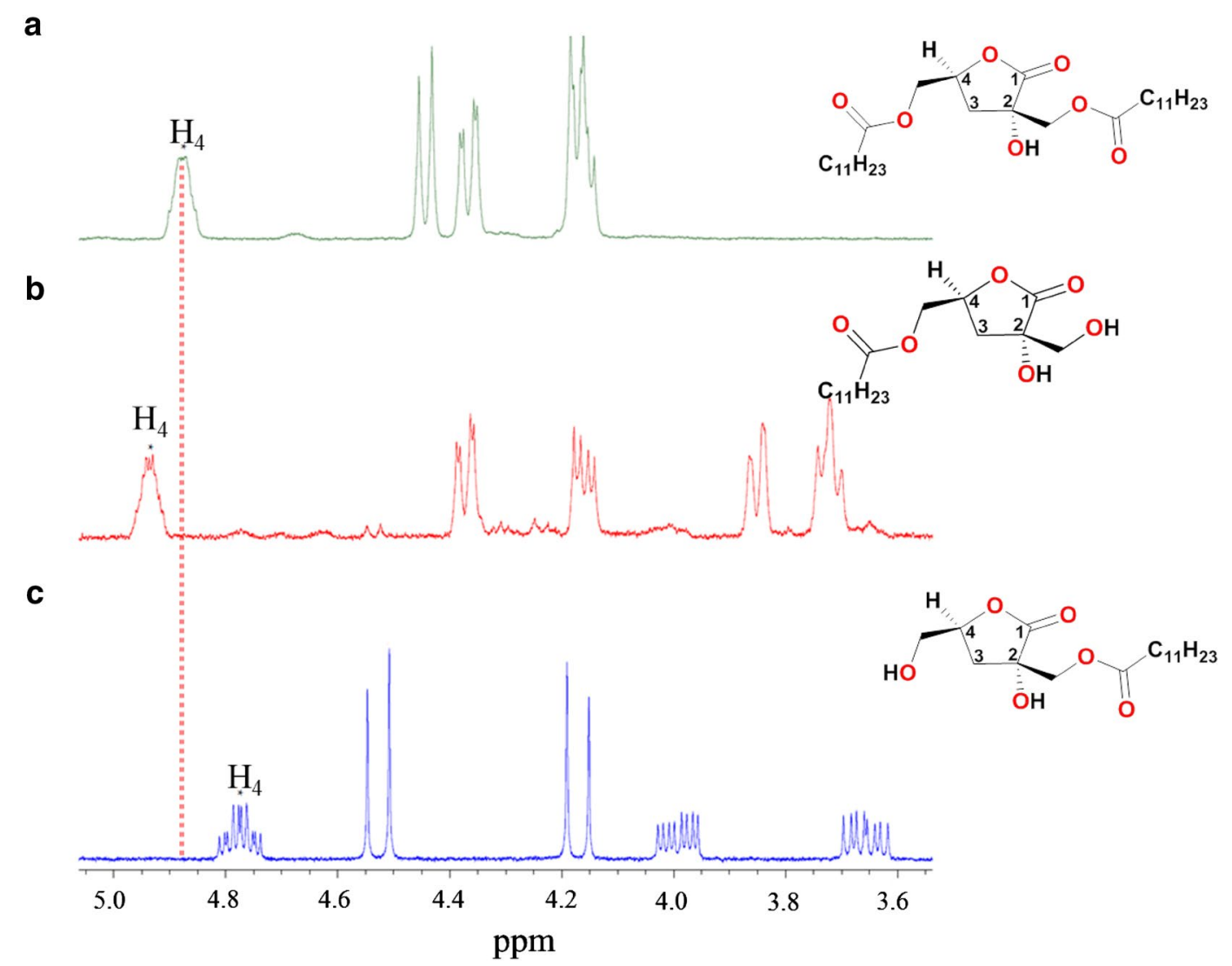

Fig. 2 Partial ${ }^{1} H$ NMR spectra of lauric acid diester $(\mathbf{a})$ and monoesters $(\mathbf{b}, \mathbf{c})$ with a-GISAL 
recovered. In general, the mutual esterification of these organic fractions to manufacture value-added nonionic surfactants seems possible.

This investigation performed with simple model substances clearly indicates that relatively high yields of mono- and diesters can by produced under optimized conditions in a microwave-assisted reactor. This new approach may offer a potential integrated biorefinery concept for utilizing more effectively wood feedstock materials with the simultaneous increase in profitability and expansion of the product portfolio of modern kraft mills.

\section{Additional file}

Additional file 1: Figure S1. HRMS (ESI+) data on mono- and diesters of a-GISAL: monolaurate (a), dilaurate (b), monooleate (c), and dioleate (d) Figure S2. IR spectra of a-GISAL and its lauric acid esters.

\section{Abbreviations}

CTO: crude tall oil; GISA: glucoisosaccharinic acid; GISAL: glucoisosaccharino1,4-lactone; HMM: high-molar-mass; LMM: low-molar-mass; pTSA: p-toluenesulfonic acid; TOFAs: tall oil fatty acids.

\section{Authors' contributions}

HK performed the experiments and analyses. RA made preliminary plan. Both authors read and approved the final manuscript.

\section{Acknowledgements}

The authors gratefully acknowledge the financial support of the Foundation for Research of Natural Resources in Finland (Suomen Luonnonvarain Tutkimussäätiö).

\section{Competing interests}

The authors declare that they have no competing interests.

Received: 22 February 2016 Accepted: 19 April 2016

Published online: 27 April 2016

\section{References}

1. Alén R (2011) Principles of biorefining. In: Alén R (ed) Biorefining of forest resources. Paper Engineers' Association, Helsinki, pp 55-114

2. Alén R (2000) Basic chemistry of wood delignification. In: Stenius P (ed) Forest products chemistry. Fapet Oy, Helsinki, pp 58-104

3. Lappi HE, Alén R (2011) Pyrolysis of crude tall oil-derived products. BioResources 6:5121-5138

4. Coll R, Udas S, Jacoby WA (2001) Conversion of the rosin acid fraction of crude tall oil into fuels and chemicals. Energy Fuels 15:1166-1172
5. Sharma RK, Bakhshi NN (1991) Catalytic conversion of crude tall oil to fuels and chemicals over HZSM-5: effect of co-feeding steam. Fuel Process Technol 27:113-130

6. Altiparmak D, Keskin A, Koca A, Guerue M (2006) Alternative fuel properties of tall oil fatty acid methyl ester-diesel fuel blends. Bioresour Technol 98:241-246

7. Holmbom B (2011) Extraction and utilisation of non-structural wood and bark components. In: Alén R (ed) Biorefining of forest resources. Paper Engineers' Association, Helsinki, pp 178-224

8. Lappi H, Alén R (2012) Pyrolysis of tall oil-derived fatty and resin acid mixtures. ISRN Renew Energy. doi:10.5402/2012/409157

9. Niemelä K, Alén R (1999) Characterization of pulping liquors. In: Sjöström E, Alén R (eds) Analytical methods in wood chemistry, pulping, and papermaking. Springer-Verlag, Heidelberg, pp 193-231

10. Kumar H, Alén R (2015) Recovery of aliphatic low-molecular-mass carboxylic acids from hardwood kraft black liquor. Sep Purif Technol 142:293-298

11. Sjöström E (1983) Alternatives for balanced production of fibers, chemicals, and energy from wood. J Appl Polym Sci Appl Polym Symp 37:577-592

12. van Heiningen A (2006) Converting a kraft pulp mill into an integrated forest biorefinery. Pulp Pap Can 107:38-43

13. Alén R (2015) Pulp mills and wood-based biorefineries. In: Pandey A, Höfer R, Taherzadeh M, Nampoothiri KM, Larroche C (eds) Industrial biorefineries \& white biotechnology. Elsevier, Amsterdam, pp 91-126

14. Alén R, Moilanen VP, Sjöström E (1986) Potential recovery of hydroxy acids from kraft pulping liquors. Tappi J 69:76-78

15. Kumar H, Alén R (2014) Partial recovery of aliphatic carboxylic acids and sodium hydroxide from hardwood black liquor by electrodialysis. Ind Eng Chem Res 53:9464-9470

16. Saarnio J, Puupponen $L$ (1971) The xylitol and other sugar fatty acid esters. Kemian Teollisuus 28:107-112

17. Sarney DB, Vulfson EN (1995) Application of enzymes to the synthesis of surfactants. Trends Biotechnol 13:164-172

18. Seino H, Uchibori T, Nishitani T, Inamasu S (1984) Enzymatic synthesis of carbohydrate esters of fatty acid (I) esterification of sucrose, glucose, fructose and sorbitol. J Am Oil Chem Soc 61:1761-1765

19. Giacometti J, Milin Č, Wolf N (1995) Monitoring the esterification of sorbitol and fatty acids by gas chromatography. J Chromatogr A 704:535-539

20. Corma A, Hamid ABS, Iborra S, Velty A (2008) Surfactants from biomass: a two-step cascade reaction for the synthesis of sorbitol fatty acid esters using solid acid catalysts. ChemSusChem 1:85-90

21. Whistler RL, BeMiller JN (1963) a-D-Isosaccharino-1,4-lactone, action of lime water on lactose. Methods Carbohydr Chem 2:477-479

22. Alén R, Sjöström E (1979) Separation of the silylated reduction products from a-D-glucoisosaccharinic acid by GLC. Acta Chem Scand 33B:693-694

\section{Submit your manuscript to a SpringerOpen ${ }^{\circ}$ journal and benefit from:}

- Convenient online submission

- Rigorous peer review

- Immediate publication on acceptance

- Open access: articles freely available online

- High visibility within the field

- Retaining the copyright to your article

Submit your next manuscript at springeropen.com 